\title{
XVIII. Observations upon luminous animals
}

\section{James Macartney Esq}

To cite this article: James Macartney Esq (1811) XVIII. Observations upon luminous animals, Philosophical Magazine Series 1, 37:154, 93-106, DOI: 10.1080/14786441108563248

To link to this article: http://dx.doi.org/10.1080/14786441108563248

$$
\text { 曲 Published online: } 18 \text { May } 2009 .
$$

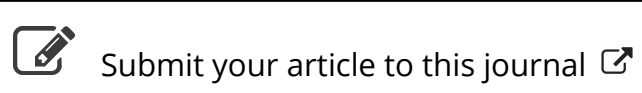

\footnotetext{
Џ Article views: 2
}

Q View related articles $₫$ 
The formulas 4 and 6 having for denominator the sine of $\left(A-A^{\prime}\right) M$. Gauss concludes that if $A=A^{\prime}$; that is to say, if the two stars have been observed in the same vertical, or in different verticals of $180^{\circ}$, the errors $d / h$ $d h^{\prime}$ will have a prodigious influence.

The same consequence may be drawn from my first formula, for it bears for its denominator the sine $W$, and in the same case $W=180$, and $\sin W=0$ like sine $\left(A-A^{\prime}\right)$.

This consequence, however, is subject to some remarkable exceptions.

For, suppose that $A=A^{\prime}$, that is to say, the two stars have been observed in the same vertical line, a single altitude will suffice, for $h-h^{\prime}=\mathrm{D}, u=180-\mathrm{V} \& \mathrm{c}$. $-u+$ $\mathrm{V}=180^{\circ}=\mathrm{W}, u$ will then be known without error, the formula $\left(3^{*}\right) d \phi=d h \cos \mathrm{A}-d u \cos h \sin \mathrm{A}$ is reduced thereby to the term $d h \cos \mathrm{A}$.

[To be continued.]

XVIII. Olservations upon Luminous Animals. By JAмвs Macartiney, Esq.

[Concluded from p. 35.]

$\mathrm{T}$ HE remarkable property of emitting light during life is only met with amongst animals of the four last classes of modern naturalists, viz. mollusca, insects, worms, and zoophytes.

The mollusca and worms contain each but a single luminous species; the pholas dactylus in the one, and the nereis noctiluca in the other.

Some species yield light, in the eight following genera of insects : elater, lampyris, fulgora, pausus, scolopendra, cancer, lynceus*, and limulus. The luminous species of the genera lampyris and fulgora are more numerous than is generally supposed, if we may judge from the appearance of luminous organs to be seen in dried specimens.

Amongst zoophytes we find that the genera medusa, bernet, and pennutula, contain species which afford light.

The only animals which appear to possess a distinct or-

* The animal discovered by Riville off the const of Malabar in 1754 is certainly a testaceous insect, and appears to belong to the genus lynceus of Müller.

+ The luminous zoophyte for which Peron has lately instituted the new genus pyrosoma, appears to me to be a buroe, and only worthy of a specific distinction.

ganization 
ganization for the production of light, are the luminous species of lampyris, elater, fulgora, and pausus.

The light of the lampyrides is known to proceed from some of the last rings of the abdomen, which when not illuminated are of a pale yellow colour. Upon the internal surface of these rings there is spread a layer of a peculiar soft yellow substance; which has been compared to paste, but by examination with a lens I found it to be organized like the common interstitial substance of the insect's body, except that it is of a closer texture, and a paler yellow colour. This substance does not entirely cover the inner surface of the rings, being more or less deficient along their edges, where it presents an irregular waving outline. I have observed in the glow-worm, that it is absorbed, and its place supplied by a common interstitial substance, after the season for giving light is past.

The segments of the abdomen, behind which this peculiar substance is situated, are thin and transparent, in order to expose the internal illumination.

The number of luminous rings varies in different species of lampyris, and as it would seem at different periods in the same individual.

Besides the luminous substance above described, I have discovered in the common glow-worm, on the inner side of the last abdominal ring, two bodies, which to the naked eye appear more minute than the head of the smallest pin. They are lodged in two slight depressions, formed in the shell of the ring, which is at these points particularly transparent. On examining these bodies under the microscope, I found that they were sacs containing a soft yellow substance, of a more close and homogeneous texture than that which lines the inner surface of the rings. The membrane forming the sacs appeared to be of two layers, each of which is composed by a transparent silvery fibre, in the same manner as the internal membrane of the respiratory tubes of insects, except that in this case the fibre passes in a spiral instead of a circular direction. This membrane, although so delicately constructer, is so elastic as to preserve its form after the sac is ruptured and the contents dischnrged.

The light that proceeds from these sacs is less under the control of the insect than that of the luminous substance spread on the rings; it is rarely ever entirely extinguished in the season that the glow-worm gives light, even during the day; and when all the other rings are dark, these sacs often shine brightly. 
The circumstance of there being points which give a more permanent light than the other parts of the luminous rings of the abdomen, has been noticed before by the Comte G. de Razoumouski. He states the number of these luminous points to vary from two to five*.

I must however remark, that I never saw more than two of these luminous points, which were always upon the last ring of the body, and that the figures which accompany the memoir of the Comte de Razoumouski bear scarcely any resemblance to the insect they are intended to represent; from which we may fairly suspect him of inaccuracy in other particulars.

As far as my observation has extended, the small sacs of luminous substances are not found in any species of lampyris, except the glow-worm of this country. Thunberg mentions that the lampyris japonica has two vesicles on the tail, which afford light.

The organs for the production of light in the genus elater are situated in the corcelet; these likewise consist of a peculiar yellow substance, placed behind transparent parts of the shell, which suffer the natural colour of this substance to be seen through them in the day, and when illuminated give passage to the light.

On dissecting the organs of light in the elater noctilucus, I fourd that there is a solt yellow substance, of an oval figure, lodged in the concavity of the yellow spots of the corcelet, which parts are particularly thin and transparent in this species. This substance is so remarkably close in its structure, that at first view it appears like an inorganic mass, but with a lens it is readily perceived to be composed of a great number of very minute parts or lobules closely pressed together. Around these oval masses, the interstitial substance of the corcelet is arranged in a radiated manner, and the portion of the shell that immediately covers the irradiated substance is in a certain degree transparent, but less so than that which lies over the oval masses: it is therefore probable, that the interstitial substance in this situation may be endowed with the property of shining. A fasciculus of the muscles of the corcelet arises in the interior of the oval masses of the luminous substance, but not apparently with any design, as it contributes, with the adjacent fasciculi, to move the anterior feet.

In the elater ignitus, the masses of luminous substance are extremely irregular in their figure: they are situated

* Mem. de la Soc. de Lausanne, tome ii. nearly 
nearly at the posterior angle of the corcelet, and are more loose in their texture than the oval masses of the noctilucus, resembling rather in composition the interstitial substance which surrounds these massez in that species: The shelf of the corcelet is somewhat thinner, and more transparent slong both sides of the margin, than at other places; but it is not, as in the noctilucus, elevated, and peculiarly clear and thin immediately over the seat of the luminous organ ; consequently, the light emitted by the elater ignitus cannot be very brilliant.

I have not been able to procure any specimen of the elater phosphorea, but from the accounts of naturalists it appears to resemble in every respect the elater noctilucus; indeed I have great doubts of the phosphorea being a distinct species.

I have had an opportunity of examining, preserved in a moist way, two species of fulgora, the candelaria and lanternaria. The light in this genus has been observed to issue from the remarkable proboscis on the fore part of the head. This part has always been described by authors as hollow or empty, which I have found to be perfectly correct; and what is more extraordinary, that the cavity communicates freely with the externai air, by means of a chink or narrow aperture, placed on each side of the root of the proboscis. This projection is covered internally by a membrané, between which and the horny part or shell there appears to be interposed a pale reddish coloured soft substance, that is arranged in the candelaria in broad lines or stripes; but it is so thin, that 1 could not distinetly examine its structure, or absolutely determine, whether it should be considered as a substance intended to furnish the light of these insects, or the pigment upon which the colour of the proboscis depends.

The globes of the antenna constitute the organs of light in the pausus spherocerus. Dr. Afzelius, who discovered the luminous property in this species, compares them to lanterns spreading a dim phosphoric light*. The rarity of the insect put it out of my power to examine its structure ; but from the form and situation of its organs of light, it is most probable they are constructed like those of the fulgoræ.

It has been conjectured by Carradori and others, that the lampyrides were enabled to moderate or extinguish their light, by retracting the luminous substance under a mero-

\footnotetext{
- Linn. Trans, vol.iv.
} 
brane; but neither in them, or any of the other luminous insects, have I found an apparatus of this sort. The substance furnishing the light is uniformly applied to corresponding transparent parts of the shell of the insect from whence it is not moved; indeed a nembrane, if it did exist, would have but litile effect in obscuring the light, and never could serve to extinguish it. The regulation of the kind and degree of the luminous appearance does not depend upon any visible mechanism, but, like the production of the light itself, is accomplished by some inscrutable change in the lnminous matter, which in some animals is a simple operation of organic life, and in others is subject to the will.

It is worthy of remark, that in all the dissections I bave made of luminous insects, I did not find that the organs of light were better or differently supplied with either nerves or air tubes, than the other parts of the body. The power of emitting light likewise exists in many creatures which want nerves, a circumstance strongly marking a difference between animal light and animal electricity.

Witt the exception of the animals above mentioned, the exhibition of light depends upon the presence of a fluid. matter.

In the pholas dactylus, the luminotis fluid is particularly evident, and in vast quantity; it is recorded by -Pliny, that this fluid is like liquid phosphorus, and renders every object luminous with which it comes into contact. Reaumur also found that it was diffusible in water, or any other fluid in which the animal might be immersed *.

The shining of the scolopendra clectrica $I$ have always observed to be accompanied by the appearance of an effusion of a luminous fluid upon the surface of the animal, more particularly about the head, which may be rcceived upon the hand, or other bodies brought into contact with the insect at the momert, and these exhibit a phosphoric light for a few seconds afterwards. This fluid, however, I never could discover in the form of moisture, even upon the clearest glass, although examined immediately with the most scrupulous attention by a lens : it must therefore be extremely attenuated.

The same appearance has been observed during the illumination of the nereis noctiluca by Fougeroux de Bondaroyt.

The animal discovered by Riville shed a blue liquor, which illuminated the water for a distance of two or three lines $t$.

* Mem. de l'Acad. des Sc. 1712.

+ Mem. Elrang. de "'Acad. des Sc. tome iï.

Vol. 37. No. 154. Fel. 1811. + Ibid. 1767. 
Spallanzani relates, that the medusa which be examined communicated the property of shiniug to water, milk, and other fluids, on being rubbed or squeezed in them*.

The luminous fluid is in some instances confined to particular parts of the body, and in others is diffused throughout the whole substance of the animal.

In the scolopendra electrica, it appears to reside immediately under the integuments. In the lynceus discovered by Riville, it is contained in the ovary. If I may judge from my own observations, every pant of the body of the medusa is furnished with this fluid, as there is no part I have not seen illuminated under different circumstances; but Spallanzani affirms that it is only found in the large tentacula, the edges of the umbella, and the purse or central mass; which he proved, he says, by detaching these parts successively, when they shone vividly, while the rest of the body neither gave light or communicated any luminous appearance to watert.

Spallanzani discovered a mucous luminous fluid in the plumule of the pennatula phosphoreat.

The phænomenon of animal light has been attempted to be explained in different ways. By many persons it was formerly ascribed to a putrefactive process; but since the modern theories of combustion became know'n, it has been generally believed to depend upon an actual inflammation of the luminous substance, similar to the slow combustion of phosphorus. Others have accounted for the luminous effect, by supposing the matter of light to be accumulated, and rendered latent under particular circumstances, and afterwards evolved in a sensible form.

The opinion of the light of living animals being the consequence of putrefaction, is evidently absurd, and contradictory to all observation on the subject. It tias been proved by the experiments of Dr. Hulme and uthers, that even the luminous appearances of dead animals are exhibited only during the first stages of the dissolution of the body, and that no light is emilted after putrefaction has really cummenced.

Spallanzani, who was the most stremuous advocate for the phosphorescent nature of animal light, stated that glowworms shone more brilliantly when put into oxygen gas; that their light gradually disappeared in hydrogen or in azotic gas, and was instantly extinguished in fixed air; that

* Spallanzani's Travels in the Two Sicilies, vol. iv.

+ Memoria sopra le medase fosforiche, Hem. della Soc. Lal. tomo vii.

I Mem. della Soc. llal. tomo ii. 
it was also lost by cold, and revived by the application of a warm temperature. He conjectured that the luminous matter of these insects was composed of hydrogen and carbouated hydrogen gas.

Forster relates, in the Lichtenberg Magazine for 1783, that on putting a lampyris splendidula into oxygen gas, it gave as much light as four of the same species in common air.

Carradori has made some experiments upon the lucciole, (lampyris italica) which led him to deny its phosphorescence. He found that the luminous portion of the belly of the insect shone in vacuum, in oil, in water, and different liquids ? and under different circumstances, where it was excluded from all communication with oxygen gas. He accounts for the result of Forster's experiment, by supposing that the worm shone more vividly, because it was more animated in oxygen gas than in common air.

Carradori adopts on this subject the doctrine of Brugnatelli, and ascribes the luminous appearances of animals to the condensation and extrication of light in particular organs, which had previously existed in combination with the substance of their bodies. He supposes the light to be originally derived from the food, or the atmospheric air taken into the body; in short, that certain animals have the peculiar property of gradually imbibing light from foreign bodies, and of afterwards secreting it in a sensible form*.

The following experiments which I made upon this subject, would lead me to make different conclusions than those of the preceding authors.

Experiment 1.-A glow-worm was put into a glass of water, in which it lived nearly two hours, and contimued to emit light as usual, until it died, when the luminous appearance entirely ceased.

Experiment 2.-The luminous substance was extracted from the beforementioned glow-worm, and from others killed in different ways, but it afforded no light.

Experiment 3.-The sacs containing the luminous matter were ctit from the bellies of living glow-worms, and shone uninterruptedly for several hours in the atmosphere, and after their light became extinct, it was revived by being moistened with water; some of these were put into water in the first instance, in which they continued to shine unremittingly for 48 hours.

* Annal di Chimica, tomo xiii. 1797.

G 2 
Experiment 4.-The luminnus substance of a glow-worm was exposed to a degree of heat which would have been sufficient to inflame phospherus, without increasing the brilliancy of its light; and further, it could not be made to burn by being applied to a red hot iron, or to the flame of a candle.

Experiment 5.-A delicate thermometer was introduced amongst some living glow-worms, during the time they gave out much light: the temperature of the room heing 69 , the instrument rose to 75,76 , and 77 , according to circumstances, as the warmth was reflected from the band, or dissipated by the worm crawling over cold substances. The luminous portion of the tail, when very brilliant, appeared to raise the thermometer more quickly than the other parts of the body, but it was not invariably the case. When shining strongly, 1 thought that the luminous rings communicated the sensation of warmth to the hand; but this was probably a deception, as the actual degree of heat was not sufficient for such an effect. It should however be mentioned, that in Templar's observations on the glowworm, he said his feelings deceived him, if he did not experience some heat from the shining of the insect*.

Experiment 6.-To satisfy myself how far the evolution of heat during the shining of glow-v'orms depended upon the life of the animals, I cut off the luminous portion of the tail from several living worms, and I found that if the thermometer was applied to them immediatety, it was raised by them one or two degrees; but after these parts were dead, although they continued to emit light, they produced no effect whatcver upon the iustrument.

Experiment 7.-Some hemispherical medusæ were put into a spoon containing a small quantity of sea water, and held over a burning candle. As soon as the water became heated the medusæ appleared like illuminated wheels, the spots at the margin and centre alone emitting light; in which manner they shone vividly and permancntly for about zo seconds, when they shrunk and died, afier which thev were no longer luminous.

Experiment 8.-Some of the same species were put into spirits: a strong and unremitting light was instantly given out, which issued from the central and marginal parts, as in the preceding experiment, and continued until they died.

Experiment 9. - Some of the scintillating and hemispherical specics of medusa, contained in a small glass jar, were 
introduced into the receiver of an air-pump, and the air being exhausted, they shone as usual when shaken; if any difference could be perceived, the light was more easily excited, and continued longer in vacuum.

I wished next to try the influence of electricity on the luminous property of animals.

Experiment 10.-A medusa hemispherica was placed in a small glass dish, containing a quantity of water merely sufficient to allow the animal to preserve its figure; being insulated, it was electrifed, and sparks drawn from it, which had not the slightest effect; the experiment was repeated several times with different individuals, but without exciting the animals to throw sut light.

Experiment 11.- Some hemispherical medusæ were placed in contact with the two ends of an interrupted chain, , and slight electric shocks passed through them. During the very moment of their receiving the shock no light was visible, but immediately afterwards the medusæ shone like illuminated wheels, which appearance remained for some seconds. Upon the closest inspection with a magnifying glass, no contractile motion could be perceived to accompany the exhibition of the light. The application of electricity in this instance seems to have acted merely as a strong mechanic shock.

The above experiments on the luminous modusa were made at Herne, with the assistance of George May, Esq. of Stroud-honse, and in the presence of a large company, capable of accurately distinguishing their results.

It seems proved by the foregoing experiments, that so far from the luminous substance being of a phosphorescent nature, it sometimes shows the strongest and most constant light, when excluded from oxygen gas; that it in no circumstances undergoes any process like combustion, but is aclually incapable of being inflamed; that the increase of heat, during the shining of glow-worms, is an accompaniment, and not an effect of the phrenomenon, and depends upon the excited state of the insect; and lastly, that heat and electricity increase the exhibition of light, merely by operating like other stimuli upon the vital properties of the animal.

In confirmation of these opinions, I may quote the high authority of the Secretary of this Sreiety, who has found that the light of the glow-worm is not rendered more brilliant in oxvgeń, or in nxygenated muriatic gas, than in conmon air; and that it is not sensibly diminished in hydrigen gas. 
I may further add, that Spallanzani's experiments of diffusing the huminous liquor of the medusa in water, milk, and other fluids, are in direct contradiction of his own theory, as is also the extinction of the light of these mixtures by the application of a high degree of heat.

If the light emitted by animals were derived from their food, or the air they respire, as supposed by Carradori, the phænomenon should be increased or dimnished, according to the quantity of food or air that the crealures consume; but we do not find this to be the case; for in those situations where they are sometines found to be most luminous, they are deprived, in a great measure, of these assumed sources of their light.

In fact, the luminous exhibitions of living animals are not only independent of all foreign light, but are frequently destroyed by the latter. I have always found the shining of the medusa to cease upon the rising of the mom, or at the approach of day; and when out of the sea, I never could excite them to throw out light until they had been kept for some time in the dark; all the luminons insects likewise secrete themselves as much as possible during the day time, and go abroad only at night. I have, it is true, found that the scolopendra electrica will not shine unless it has been previously exposed to solar light; but I have observed that it shone as brilliaully and as frequent?y, after being kept a short timie in a light situation, as when left uncosered the whole day. The circumstance of the scolopendra requiring exposure previous to its giving out light, is very unaccountable, as the insect, when left to itself, always seeks as much as possible concealment during the dav; indeed it is the cpinion of some naturalists that it is killed by the light of the sun.

The opinions of Brugnatelli and Carradori are connected with some gencral doctrines, respecting the nature of light, which I shall not at present venture to discuss. It appears to me, that the question is still unresolved, whether light has a substantial existence, or is a phanomenon depending upon certain operations or conditions of the ordinary forms of inatter. But the highly ingenious researcbes of Count Rumford, on the laws of what have been called subtile fluids, and the extraordinary advances lately made by Mr. Davy, on the decomposition of subetances that were hitherto looked upon as elementary, give us reason to hope, that future investigations may unfold views of the matrial world, of which we can at present have only an indistinct conception; that new mudes of analysis may enable us to see things, 
things, not " through a glass darkly," but more nearly as they are; and that the boundaries of physical and metaphysical science, now so far asunder, may be made to approach each other.

In the present state of our knowledge, our business should be, to collect, arrange, and compare phænomena, rather than to speculate upon their nature. Nevertheless, I cannot refrain from observing, that the circumstances attending the luminous appearance of living animals, are much more favourable to the supposition of light being a property than a substance. The quantity of light emitted by an animal in a cerlain time, (admitting it to be matter) far exceeds that which could be possibly supplied by the sources from whence it is usually supposed to be derived. Thus the lyminous appearance of some medusæ may be continued with the intermission of short intervals for an indefinite time, notwithstanding the creature be kept in darkness, and without any other food than what a small quantity of filtered sea- $n$ ater would afford. The uninterrupted and long continued light that is sometimes evolved by the luminous sacs, and the ova of the glow-worm, is also inconsistent with the notion of an accumulation and subsequent dispersion of a material substance.

I sball terminate this paper by an enumeration of the several conclusions, that are the result of the observations I bave been able to make upon the phænomena of animal light.

The property of emitting light is confined to animals of the simplest organization, the greater number of which are inhabitants of the sea.-The luminous property is not constant, but in general exists orly at certain periods, and in particular states of the anlmal's body. - The power of showing light resides in a peculiar substance or fluid, which is sometimes situated in a particular organ, and at others diffused tbroughout the animal's body. - The light is differently regulated, when the luminous matter exists in the living bouly, and when it is abstracted from it. In the first case, it is intermitting, or alternated with periods of darkness; is commonly produced or increased by a muscular effort; and is sometimes absolutely dependent upon the will of the animal. In the second case, the luminous appearance is usually permanent until it becomes extinct, after which it may be restored directly by friction, concussion, and the application of warmth; which last causes operate on the Juminous matter (while in the living body,) only indirectly, by exciting the animal. - The luminous matter, in all situ- 
ations, so far from possessing phosphoric properties, is in. combustible, and loses the quality of emitting light, by being dried, or much heated.-The exhibition of light, however long it may be continued, causes no diminution of the buik of the luminous matter. It does not require the presence of pure air, and is not extinguished by other gases.

The luminous appearance of living animals is not exhausted by long continuance, or frequent repetitions, nor accumulated by exposure to natural light; it is therefore not dependent upon any foreign source, but inheres as a property, in a peculiarly organized animal substance or fluid, and is regulated by the same laws which govern all the other functions of living beings.

The light of the sea is always produced by living animals, and most frequently by the presence of the medusa scintillans. When great numbers of this species approach the surface, they sometimes coalesce together, and cause that snowy or milky appearance of the sea, which is so alarming to navigators. These animals, when congregated on the surface of the water, can produce a flash of light, some what like an electric coruscation. When the Juminous medusa are very numerous, as frequently happens in confined bays, they form a considerable portion of the mass of the sea, at which times they render the water heavier, and more nauseous to the taste; it is therefore adviseable to always strain sea-water before it is drunk.

The luminous property does not appear to have any connection with the ceconomy of the animals that possess it, excepting in the flying insects, which by that means discover each other at night, for the purpose of sexual congress.

\section{Explanation of the Figures (Plates I and II.)}

Fig. 1. The cancer fulgens, discovered by the Right Hon. Sir Joseph Banks, of the natural size.

Fig. 2. The same animal magnified.

Fig. 3. The medusa pellacens, also found by Sir Joseph Banks, represented of the natural magnitude.

Fig. 4. The limulus noctilucus, discovered by Captain Horsburgh, considerably enlarged.

Fig. 5. The luminous medusa, discovered by me, which I conceive to be the merlusa hemispherica: it is shown of the largest size I met with.

Fig. 6. The central process of this animal's body magnifed, in order to explain its structure. The thick tentacula 
Phil.Mag. Vol.XXXVII Rl.1.

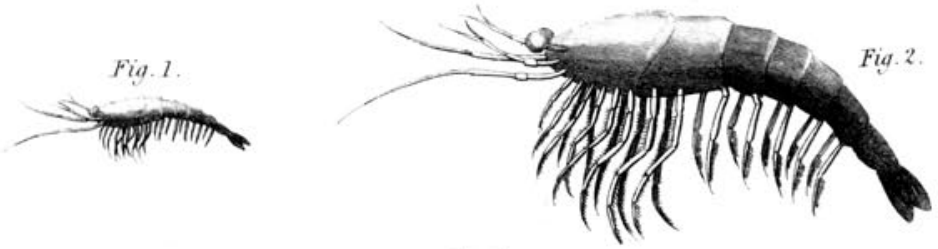

Fig. 3.

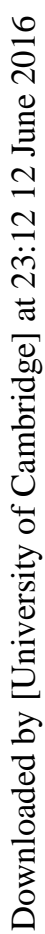
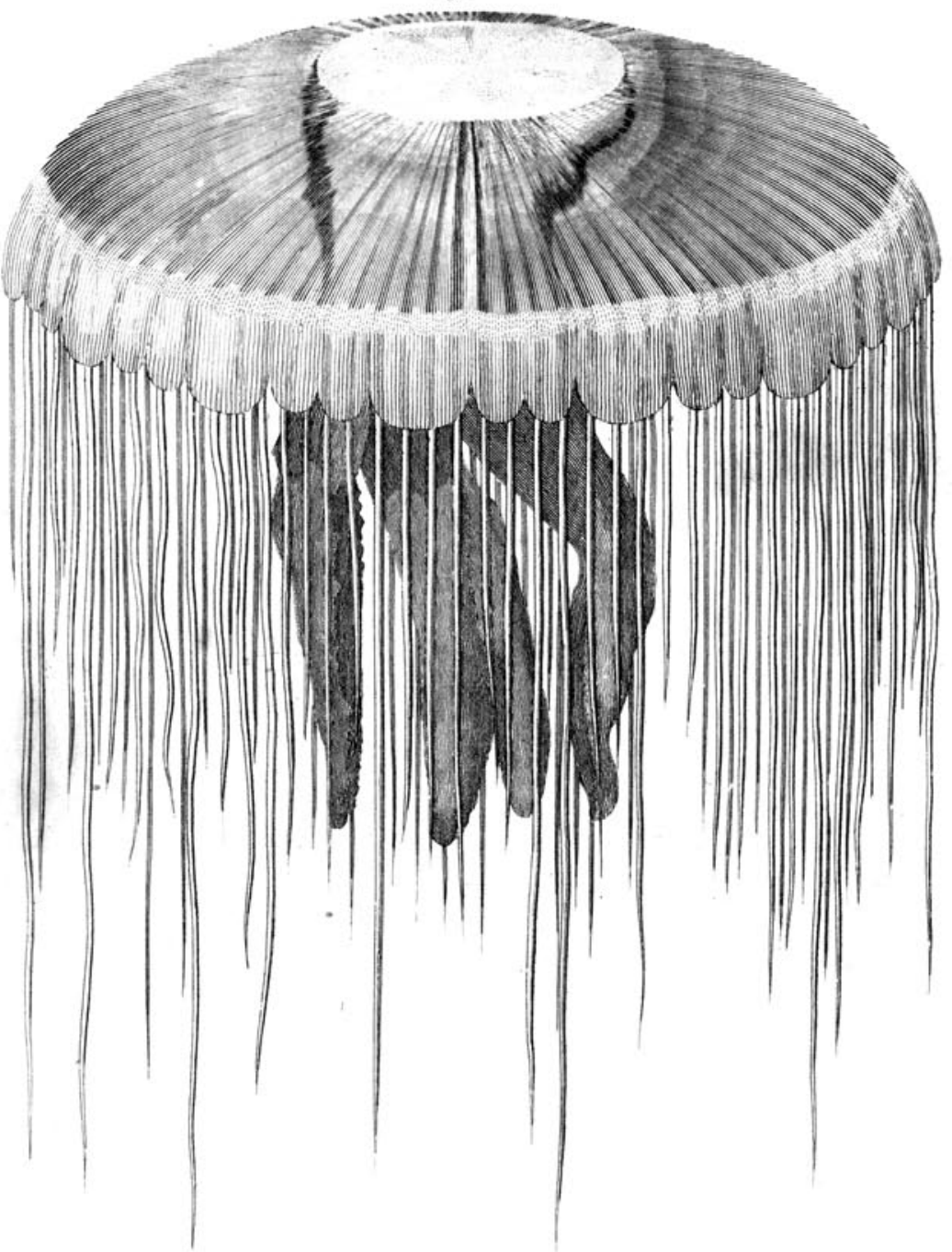
Phit Alay. Wh XXXYII P! ?

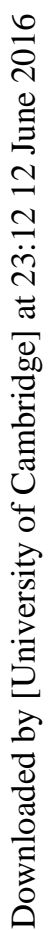
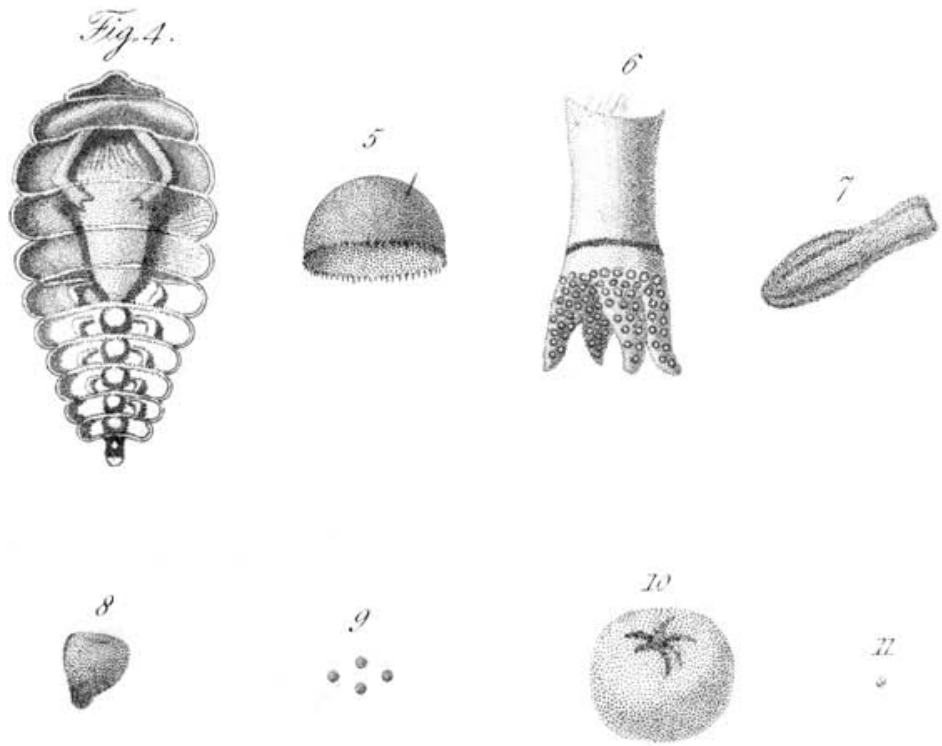

13
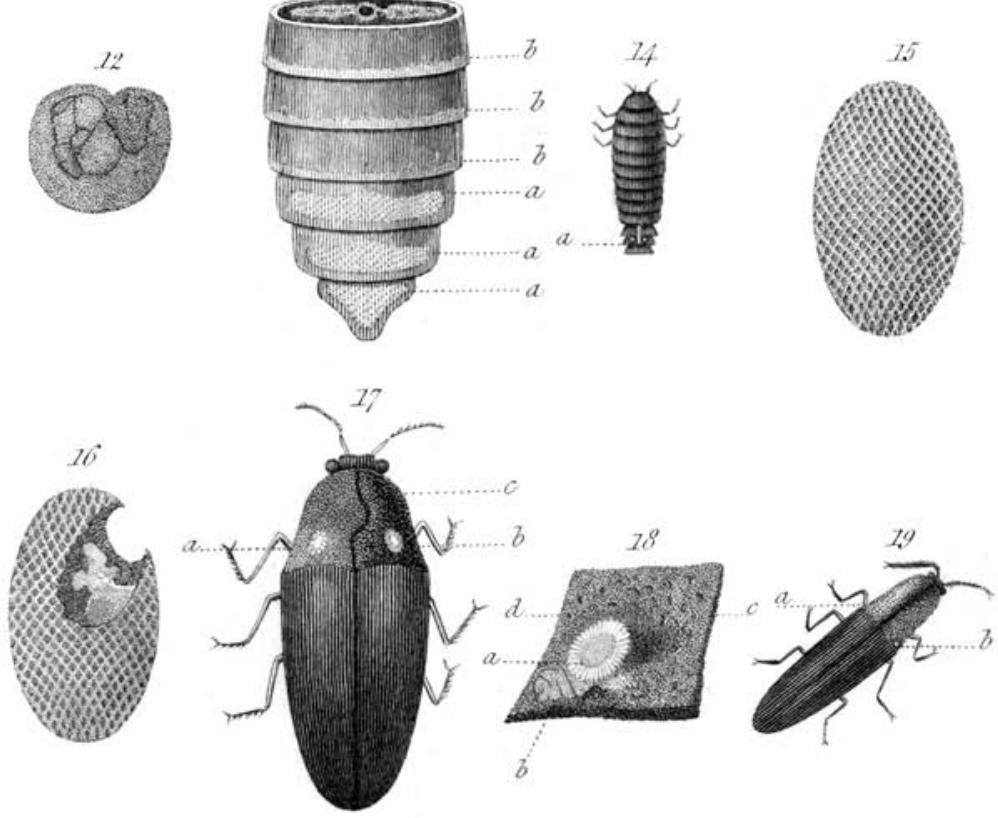

SPinter

Lis. 
in which it terminates are seen covered with small cups or suckers.

Fig. 7. The beroe fulgens, discovered by me, shown in its most elongated or relaxed form, which it assumes counmonly when swimming quickly.

Fig. 8. The same animal in the most contracted form.

Fig. 9. The minute species of medusa, discovered by me, which is the most frequent cause of the luminous appearance of the sea, represented of the natural size.

Fig. 10. The same animal magnified, exhibiting a puckered or tucked-in appearance on one side.

Fig. 11. Is the animalcule discovered by Forster, of the natural size.

Fig. 12. The same, greatly magnified, to show the intestinal parts. Both these figures are copied from the original drawings, in the possession of the Right Hon. Sir Joseph Banks.

Fig. 13. Is an enlarged view of the inferior surface of the abdomen of the lampyris lucida, after the integument had been removed. a a a represent the three masses of luminous substance which are applied to the three last rings of the abdomen. $b b b$ the arrangement of cellular or interstitial substance on the other abdominal rings, which gives the pale colour to the whole belly of this insect.

Fig. 14. Represents the common glow-worm, with the posterior portion of the back cut away to expose the sacs of luminons matrer in situ on the last ring of the belly. $a$ indicates the sac of one side; the intestine is seen to lie between them.

Fig. 15 and 16. Are the sacs of the glow-worm prodigiously magnified to show their structure. Fig. 16 is cut open to expose the luminous matter it contains : the coat of the sac is still seen to preserve its figure.

Fig. 17. Is the elater noctilucus, with the shell of the corcelet removed on one side, by which the organ of light is uncovered, $a$ the yellow transparent spot of the corcelet. $b$ the oval mass of luminous substance surrounded by an irradiation of the interstitial substance. $c$ the ends of the muscles which were on the inside of the corcelet.

Fig. 18. Is the posterior angle of the corcelet of the elater noctilucus magnified. $a$ the radiated appearance which the interstitial substance has round the oval mass of luminous matter. This mass is seen to consist of a number of smaller parts. $b$ shows the appearance of the interstitial substance, where it passes down between the muscles. $c$ the ends of the inuscles of the back. $d$ the shell of the corcelet. 
Fig. 19. Represents the elater ignitus. $a$ is the mass of luminous substance of one side, seen indistinctly through the back part of the semitransparent portion of the corcelet. $b$ is the luminous mass of thie other side, exposed by removing a part of the shell of the corcelet.

XIX. $A$ List of alout 280 Mines of Lead,-some with Zinc, Manganese, Copper, Iron, Fluor, Barytes, $\$ c$. in and near to Derbyshire. By Mr. John Farey, Sen., Mineralogical Surveyor.

Sir, I Inclose a list of such mineral Veins or Mines as bave been visited or information obtained concerning, in the course of the mineral Survey in which $I$ have been engaged, since the year 1807: I do not offer it as a complete Jist of the mines, but as a selection from the most productive and important ones, or those which are calculated to illustrate some point of interest, in the progress of mining, or in a geological view. As I observed respecting the List of Collieries (in your 35th volume, page 432), many of these Mines were long ago discontinued, but as in most instances, further quantities of ore lay in the deep, below level or beneath the toadstone strata, the recording of such, may not be without its uses. In the manuscript of the first volume of my Report, which is now printing by order of the Board of Agriculture, I have given an alphabetical list of these mines, with the most important or remarkable products, and particulars respecting each; which mines all produce blue lead ore or galena, I believe, and the greater part of them in rake-veins in the limeston. rocks; and I there distinguish, the other variable and more rare particulars, such as pipe-veins, flat-works, and in which of the limestone rocks or toadstones, $\mathrm{Ac}$. they occur; galena being found in toadstone between the limestones, or in the sbale above them; white or green ores of lead, or silver combined therewith in notable quantities: copper ore, calamine, black-jack, black-wad, pyrites (iron), nchres; fluor spars, blue-john, barytes, calcareous crystals; sulphur, bitumea, petroleum; china-clay, steatite; cherts, toadstones, or clay-wayboards in the strata or veins : crooked, crossing, laaded or squinted rakes; caverns, slickensides, faults, gravel or extraneous fossils in the veins, \&c.

Without doubt, some mines that present instances, and perhaps, striking oncs, of the particular phænomena mentioned abóve, or perhaps other curious ontes, have escaped 